\title{
Failure Analysis of Steam Pipe Flange Gasket
}

\author{
Wei Liu ${ }^{1, a}$ and Hehui Wang ${ }^{1, b}$ \\ ${ }^{1}$ School of Mechanical and Power Engineering, East China University of Science and Technology, \\ Shanghai, 200237, China \\ awerkessy2012@163.com, ${ }^{\mathrm{b}}$ hhwang@ecust.edu.cn
}

Keywords: serrated gasket, failure analysis, residual stress.

\begin{abstract}
Flange at the end of steam line in the Co coking joint unit became invalid in a normal operation at a petrochemical corporation. The failure mechanism was fatigue fracture failure by means of gasket macro analysis, chemical composition analysis, metallographic analysis, fracture analysis and energy spectrum analysis. The reason was that residual stress existed in serrated gasket. The improving measure was put forward to prevent the failure in serrated gasket.
\end{abstract}

\section{Introduction}

The steam pressure of the Rich Gas Compressor was found reduced from 3.5MPa to 2.7MPa during the normal operation of the 240 thousand ton / year coking unit combined in No.2 refinery, a load roar outside the instrument was heard at the same time. It was showed that the flange at the end of the boundary leaked, a great quantity of high temperature and high pressure steam sprayed from the flange sealing surface, The spray area is uniformly distributed around the circumference, so it can be judged that the flange seal was all invalid. Operating pressure is 3.5MPa, temperature is $350^{\circ} \mathrm{C}$, the material of the pipeline and the flange matching boundary valve is $15 \mathrm{CrMo}$.

The site is gasket + blind + gasket clamp structure, instead of the conventional gasket structure, sandwiched between a 45mm thickness of eight blind plate, an increase of 2 sealing surface, so the structure in the whole pipe system belongs to the weak parts.

\section{Failure analysis of gasket cracking}

\section{Macro analysis.}

After the failure of the flange open, found that the blind side of the plate gasket cracking, figure 2 showed the cracked flange gasket macro photo, it can be seen that the failure gasket has been broken, and the deformation of the gasket has occurred, and the crack of the gasket is extended along the circumferential direction as well as the crack extending along the radial direction. The other side of the blind flange gasket is basically intact, no deformation and cracking. There is no obvious plastic deformation at the fracture surface, which shows the characteristics of macro brittle fracture.

Further observation, it is found that the crack location of radial and circumferential cracks is located at the sixth grooves of the inner diameter of the gasket, as shown in Figure 3. The radial crack extends along the circumferential direction, also extends along the radial direction, and then through the entire gasket in radial direction. At the same time it can be seen that the failure gasket at the convex ring of the fracture site has been severely crushed, the inner diameter parts almost flattened, showing the plastic deformation is greater than that of other parts. It indicates that gasket of this part is subjected to higher pressure from the flange body. It can be speculated that the bolt pretension is not uniform in the pre tightening process of the flange bolt. 


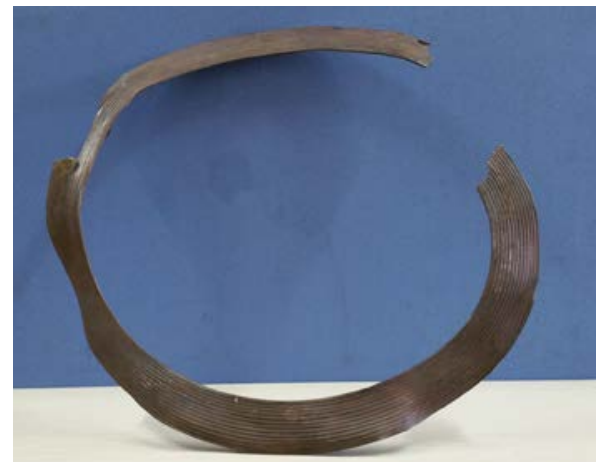

Fig. 1 Failure flange gasket

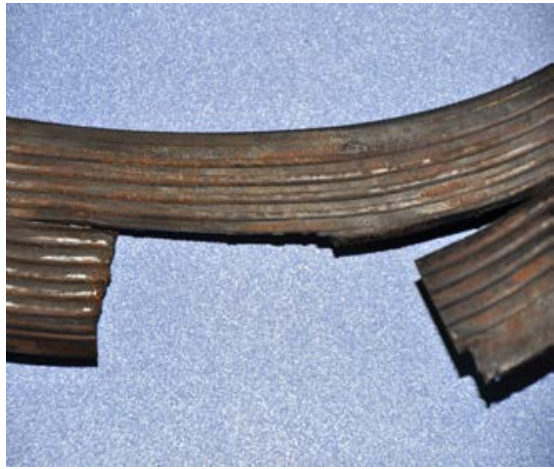

Fig. 2 Circumferential crack

\section{Chemical composition analysis.}

The cracking gasket material is 304 stainless steel, and the chemical composition of the cracking gasket is measured by spectral method. The results are shown in table 1. Chemical composition conforms to the standard, gasket material no problem.

Table 1 test results of chemical composition of gasket

\begin{tabular}{|c|c|c|c|c|c|c|c|c|}
\hline Element & $\mathrm{C}$ & $\mathrm{Si}$ & $\mathrm{Mn}$ & $\mathrm{P}$ & $\mathrm{S}$ & $\mathrm{Cr}$ & $\mathrm{Mo}$ & $\mathrm{Ni}$ \\
\hline $\begin{array}{c}\text { Content } \\
(\%)\end{array}$ & 0.0484 & 0.395 & 1.00 & $<0.004$ & $<0.002$ & 17.9 & 0.044 & 8.08 \\
\hline
\end{tabular}

\section{Metallographic analysis.}

Sampling of the radial cracking occurred on the gasket and metallographic examination. Figure 4(A and B were respectively the magnification of 50 and 200 times) was the crack at the metallographic photos. The material is austenite, and a lot of grains can be seen in the grains. From the macroscopic analysis, the main crack presents the transgranular expansion along the radial direction $^{[1]}$, and the crack has a slight bifurcation in the expansion process, and the crack tip is blunt.

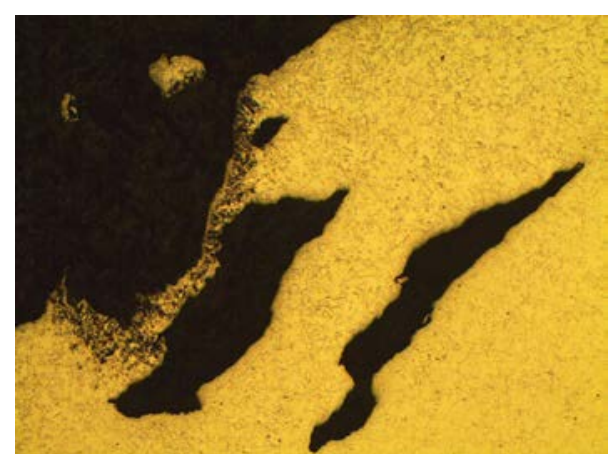

(a) $50 \times$

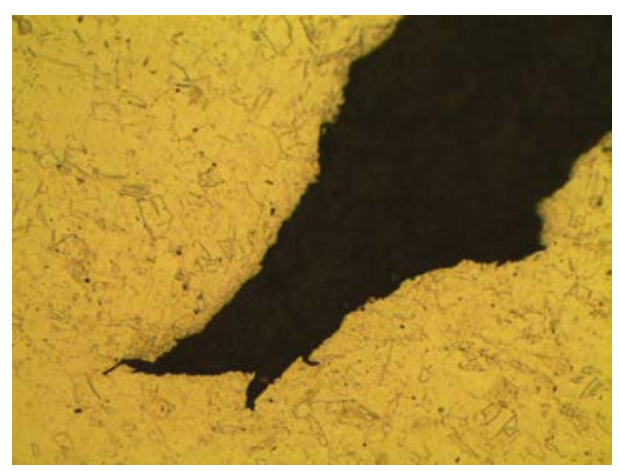

(b) $200 \times$

Fig. 3 Crack at fracture

Figure 5(A and B were respectively the magnification of 50 and 100 times) was the micro crack near the fracture. It can be seen that there are many micro cracks in the microstructure, some of which are vertical to the main crack, and some are still in the crack propagation period.

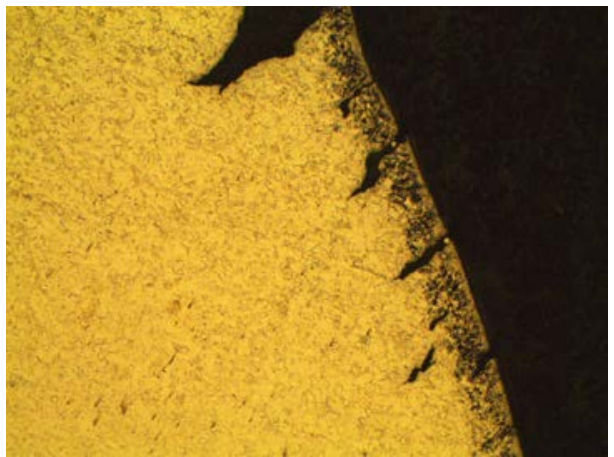

(a) $50 x$

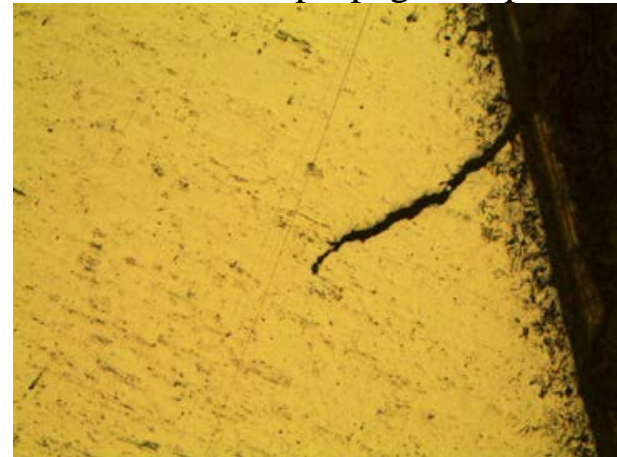

(b) $100 \times$

Fig. 4 Micro-crack near fracture 


\section{Fracture and energy spectrum analysis.}

Scanning electron microscopy can be modulated imaging by physical signals which is excited by the scanning electron beam on the sample surface, the intensity and distribution of the obtained information are related to the surface morphology and surface state of the samples. The microscopic morphology of the samples can be characterized by observing the information received by SEM ${ }^{[2]}$. The fracture surface was sampled and cleaned by ultrasonic acetone, and the fracture surface was observed by SEM, as shown in figure 6(A and B were respectively the magnification of 200 and 1000 times). It can be seen that the whole fracture is characterized by brittle fracture, and there is almost no typical dimple. In the magnification of 1000 times, it can be seen that there is fatigue striations, which indicates that the fracture is fatigue.

Energy spectrum analysis of fracture surface, the results are shown in figure 7, it can be seen that there are a small amount of $\mathrm{Cl}, \mathrm{S}, \mathrm{Ca}, \mathrm{Na}, \mathrm{Mg}$ and other elements in the fracture surface, indicating that there is corrosion in the fracture surface. These components are likely to come from the steam.

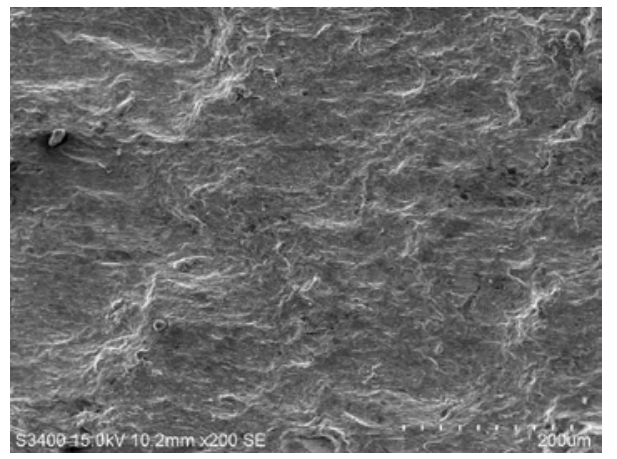

(a) $200 \times$

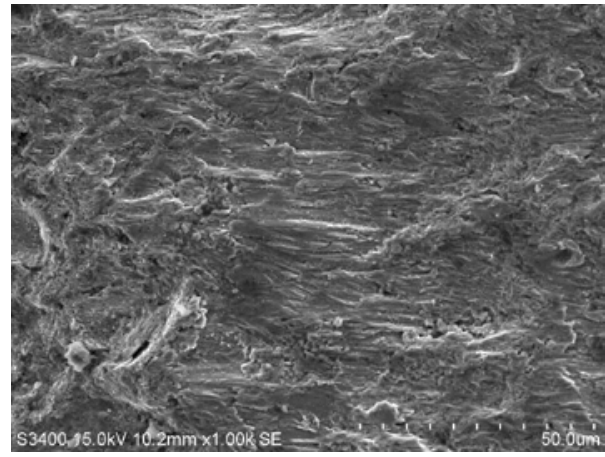

(b) $1000 \times$

Fig. 5 SEM at fracture

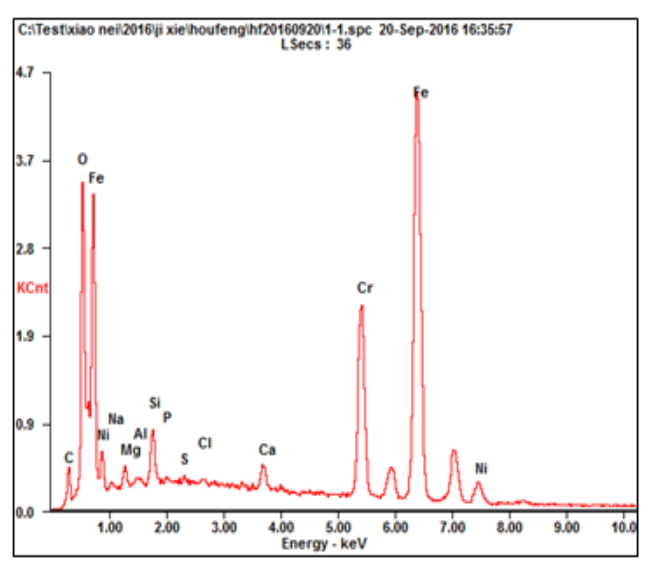

\begin{tabular}{||l|l|l|}
\hline Element & $\boldsymbol{W t} \%$ & \multicolumn{1}{|c|}{ At \% } \\
\hline $\boldsymbol{C} \boldsymbol{K}$ & 02.72 & 09.68 \\
\hline $\boldsymbol{O} \boldsymbol{K}$ & 06.49 & 17.36 \\
\hline $\mathbf{N a K}$ & 00.29 & 00.55 \\
\hline $\boldsymbol{M g K}$ & 00.57 & 01.01 \\
\hline $\boldsymbol{A L K}$ & 00.17 & 00.28 \\
\hline $\boldsymbol{S i K}$ & 01.35 & 02.05 \\
\hline $\boldsymbol{P} \boldsymbol{K}$ & 00.07 & 00.10 \\
\hline $\boldsymbol{S} \boldsymbol{K}$ & 00.13 & 00.17 \\
\hline $\boldsymbol{C} \boldsymbol{K}$ & 00.18 & 00.21 \\
\hline $\mathbf{C a K}$ & 01.06 & 01.14 \\
\hline $\boldsymbol{C r} \boldsymbol{K}$ & 17.57 & 14.47 \\
\hline $\mathbf{F e} \boldsymbol{K}$ & 63.36 & 48.58 \\
\hline $\mathbf{N i K}$ & 06.04 & 04.40 \\
\hline \hline
\end{tabular}

(a) Energy spectrum

(b) Element percentage

Fig. 6 Results of energy spectrum analysis at fracture

\section{Comprehensive analysis}

304 stainless steel is a kind of better austenitic stainless steel, the yield ratio is very low ${ }^{[3]}$. Micro morphology of fracture surface is found no obvious plastic deformation, and the obvious fatigue line can be observed. The crack tip is blunt, the crack is mainly crystal extension and the crack has no obvious bifurcation ${ }^{[4]}$.

The Brinell hardness of the bolt rod is about 290, and the standard value is 241, it showed that the hardness of the bolt was increased, the occurrence of brittle and creep, and the mechanical properties were decreased, which cannot meet the requirements of the temperature and pressure fluctuations under the working conditions, coupled with the gasket rupture, resulting in serious leakage of flange ${ }^{[5]}$.

It is concluded that the failure process of the gasket is composed of 3 stages: 
(1) In the process of cold pad processing, the groove surface is not smooth enough, the residual stress has not been effectively released, there are micro cracks or surface defects in the sixth groove.

(2) In the process of flange installation, the bolt pre tightening force of the fracture part of the gasket exceeded the other parts', which caused the compression stress of the gasket was too large.

(3) In the service process, the assembly stress and thermal stress superposition, and high temperature steam corrosion. The stress concentration of the groove was sensitive to the pressure and temperature fluctuation on the operation process, there was a high stress fluctuation, persistent fatigue stress induced crack expansion, eventually leaded to brittle fatigue fracture.

\section{Conclusions}

Based on the results of the above experiments, it can be seen that the cracking of the toothed gasket was a typical brittle crack, and the crack was mainly transgranular expansion.

It is suggested that measures should be taken from the following two aspects in order to prevent the failure of the serrated gasket.

(1) Improving the processing and heat treatment process of the serrated gasket, ensuring the smooth surface of the groove, strengthening the control of the heat treatment process, and eliminating the residual stress, so as to ensure the strength of the gasket.

(2) When the flange is installed, it is necessary to ensure that the flange bolt pre tightening force is moderate and uniform. After working for a period of time, the bolts need to be properly tightened to eliminate the influence of assembly deformation and creep relaxation on the bolt tightening force. The gasket material can be upgraded to 316L to improve the anti fatigue performance.

\section{References}

[1] Tianhua chemical machinery and automation research and Design Institute. Corrosion and Protection Manual(Vol.1)[M]. Beijing: Chemical Industry Press,2008.

[2] Y.Z.Wang and X.X.Hou, Application of Scanning Electron Microscope with Energy Spectrum Analysis in Material Analysis [J]. Manufacturing Technology \& Machine Tool.2007(In Chinese).

[3] Y.Han and X.D.Chen, Study on strain hardening process and properties of austenitic stainless steel [J]. Chinese Journal of Mechanical Engineering.2012(In Chinese).

[4] D.Zhang and P.D.Zhong, failure analysis [M]. Beijing: National Defence Industry Press, 2000(In Chinese).

[5] H.Xu, S.H.Zheng and Malle Karl, Study on High Temperature Creep Rupture of Cylinder Fastening Bolt of Super (Super) Critical Steam Turbine [J]. Transactions of China Electrotechnical Society.2007. 